\title{
Un cuestionamiento del mito del puente cultural: la traducción como embudo y el ejemplo de la poesía costarricense ${ }^{1}$
}

\section{(Questioning the Myth of Cultural Bridges: Translation as a Funnel and the Example of Costa Rican Poetry)}

Javier Franco Aixelá ${ }^{2}$

Universidad de Alicante, España

Francisco Vargas Gómez ${ }^{3}$

Universidad Nacional, Costa Rica

\section{resumen}

La traducción se ha presentado como puente cultural, como medio neutral y democratizador al servicio de la comunicación y el intercambio intercultural. Tal función se realizaría de manera indiscriminada con respecto a la producción cultural de los espacios involucrados. Las teorías modernas la visualizan como una práctica selectiva, sujeta a intereses particulares, que ofrecen una visión sesgada del polo de partida. Este estudio muestra la función de embudo perpetuador de desequilibrios globales e imágenes predeterminadas que cumple la traducción y pone en entredicho el mito del puente cultural. Se da como ejemplo las traducciones de poesía costarricense durante el siglo xx, centradas en determinadas manifestaciones y escritores, a expensas de otros.

1 Elaborado con base en la ponencia presentada por los autores en el IV Congreso Internacional de Lingüística Aplicada, llevado a cabo en mayo de 2013, en el Campus Omar Dengo, de la Universidad Nacional de Costa Rica. Recibido: 19 de mayo de 2012; aceptado: 13 de agosto de 2012.

2 Correo electrónico: Javier.Franco@ua.es

3 Escuela de Literatura y Ciencias del Lenguaje. Correo electrónico: vargasgomezfrancisco@ gmail.com

$$
L_{\text {etras }} 52 \text { (2012), ISSN 1409-424X }
$$




\begin{abstract}
Making no difference between cultural productions of either original or target contexts, translation has been viewed as a cultural bridge, a neutral and democratizing means at the service of communication and intercultural exchange. Modern theories now conceptualize this activity as a selective practice, one that is subject to particular interests and that offers an incomplete picture of the original context. Our objectives here are to show the function of translation as a funnel perpetuating global imbalances and pre-established images, and to question the myth of the cultural bridge. We analyze the case of twentieth-century Costa Rican poetry, in which translations focused almost exclusively on specific trends and poets, while others were left aside.
\end{abstract}

Palabras clave: traducción, puente cultural, embudo, poesía costarricense Keywords: translation, cultural bridge, funnel, Costa Rican poetry

\title{
Cuestionamiento del mito del puente intercultural neutro: el ni- vel cuantitativo
}

En cada ocasión en que tiene lugar un acto público en torno a la traducción, como pueden ser inauguraciones y clausuras de cursos universitarios o entregas de premios a traductores, indefectiblemente la autoridad al cargo de la ceremonia introduce en su discurso palabras laudatorias a nuestro oficio en las que se presenta la traducción como puente entre culturas, facilitadora del conocimiento entre los pueblos, democratizadora de las relaciones internacionales $\mathrm{y}$, por consiguiente, arquitecta de la paz mundial, si no más.

Como suele suceder con casi todos los clichés, esta tesis no deja de tener su parte de verdad, condición necesaria para la conservación de un lugar común como este a lo largo de los siglos. Efectivamente, sin traducción el conocimiento del otro, esto es, la conciencia de que existen otras maneras de ver el mundo y de (re)presentarlo, sería sencillamente inviable más allá de unos pocos individuos especialmente inquietos e ilustrados. En ese sentido, la traducción desempeña un papel primordial en las relaciones entre los pueblos, que de otro modo se verían condenados a ignorarse casi por completo. La 
traducción ha sido y es el eslabón imprescindible que nos ha permitido disfrutar de nuevos géneros literarios, enfoques filosóficos, conocimientos científicos y hasta alfabetos enteros creados ex novo para posibilitar la introducción de textos centrales como la Biblia. Lo mismo sucede con el flujo del conocimiento, especialmente el científico. Sin traducción, el desarrollo del conocimiento sería torpe y fragmentario y, sobre todo, no alcanzaría a los no expertos ni a los ciudadanos desconocedores de la lengua franca del momento.

Sin embargo, pese a la traducción, también es cierto que la inmensa mayoría de la población mundial con acceso a los libros y a los medios de comunicación de masas como el cine sabe lo que es una hamburguesa y que el día de Acción de Gracias en Estados Unidos lo habitual es comer pavo, mientras que lo que se come por Navidad en España o Costa Rica, o las costumbres culinarias de un país tan inmenso como Rusia están limitadas a la población local de esos países, junto quizá a una reducidísima minoría de viajeros e intelectuales con inquietudes culturales. Esto parece apuntar a un desequilibrio en el intercambio mundial de los productos culturales y del conocimiento al que la traducción no es capaz de poner coto pese a sus grandes virtudes recién glosadas.

Resulta obvio que las relaciones de poder entre los aproximadamente doscientos países que forman el mundo no destacan por su igualitarismo, y eso por no hablar de las regiones que componen esos países, entre las cuales con frecuencia también hay desequilibrios patentes. En este sentido, lo sorprendente sería que la traducción fuese esencialmente distinta y realmente constituyera un instrumento sistemático de compensación o resistencia. Por desgracia, la traducción no deja de ser una actividad humana tan sujeta a las convenciones sociales como las demás y, en ese sentido, suele actuar como correa de transmisión del estado de las cosas. La mención de una única cifra comparativa resulta muy ilustrativa al efecto. En la actualidad, por ejemplo, en España aproximadamente un $25 \%$ de los libros son 
traducciones (cf. Libro blanco de la traducción editorial en Espa$\tilde{n} a^{4}$ ), mientras que en Estados Unidos o Gran Bretaña (cf. Venuti, 1998) esa cifra ronda el $3 \%$, y esto sin entrar en la cuestión de que el nicho cultural de superventas que adoptan tantas traducciones en España no es comparable al espacio minoritario que tradicionalmente suelen ocupar las traducciones al inglés. Las cifras son similares para todos los países europeos con la salvedad de Gran Bretaña y es de suponer que muestren un desequilibrio aún mayor en Latinoamérica, especialmente en países pequeños como Costa Rica, huérfanos de una potente industria editorial propia y dependientes a su vez de países como México o España.

Por lo demás, la situación actual no parece demasiado novedosa, ya que el carácter de lengua franca que tuvieron el latín en la Edad Media o el francés durante el siglo xix y primera mitad del xx nos sugieren que este desequilibrio debe ser bastante habitual en la historia de la traducción y las relaciones interculturales. Lo cierto es que en paralelo a su carácter de puente entre culturas, la traducción también desempeña una y otra vez un papel de refuerzo de los desequilibrios globales, no está muy claro en qué medida como causa y en cuál como consecuencia inevitable. Si como hemos visto el conjunto del mundo alfabetizado y buena parte del analfabeto sabe perfectamente qué se come en Oklahoma el día de Acción de Gracias, si el género actualmente de moda es la historia-ficción con tintes religiosos o si tantas otras cosas, la traducción siempre se alza como mecanismo privilegiado de transmisión de todos esos valores, que tienden hacia lo globalizado en un sentido muy unilateral de la palabra.

\section{El nivel cualitativo del embudo}

El carácter potencialmente desequilibrante de la traducción se manifiesta en dos niveles claramente diferenciables. Por un lado, está el plano cuantitativo al que acabamos de hacer referencia y que

4 Varios autores, Libro blanco de la traducción editorial en España (AceTT, 2010. Web. 25 de febrero de 2013). 
explica la perpetuación de un desequilibrio en cuanto al conocimiento de los otros en general, estableciéndose potencias hegemónicas que en las distintas áreas geopolíticas utilizan la traducción para exportar su cosmovisión. Conviene añadir aquí que estas potencias culturales y políticas son perfectamente conscientes de la importancia estratégica de su hegemonía cultural, como demuestra su preocupación por consolidarla a través de medios de comunicación internacionales y de instituciones diseñadas para la enseñanza de su lengua en el extranjero, así como por la atracción de estudiantes extranjeros a sus países, de modo que luego extiendan en sus sociedades de origen la cosmovisión adquirida.

También cabe situar el sesgo en el conocimiento del otro en un plano cualitativo que como investigadores de la traducción nos afecta especialmente: los criterios de selección de lo que efectivamente se traduce y el modo en que se traducen los textos como manera de dar visibilidad al otro, de distorsionarlo o, sencillamente, de ocultarlo.

En cuanto a los criterios de selección, que se corresponden con parte de las normas preliminares postuladas por Toury ${ }^{5}$, la idea básica consiste en comprender que no sólo no se traduce todo lo que se produce fuera -ni siquiera lo procedente de las potencias hegemónicas correspondientes-, sino que la traducción implica un proceso de selección por el que cada cultura importa únicamente o bien aquello que cubre alguna necesidad cultural o, sobre todo, económica, o bien aquello que le impone alguna potencia mediante diversos mecanismos de exportación. En este último sentido, es conocida en España la política de las distribuidoras cinematográficas de Hollywood, que tienen tendencia a obligar de manera más o menos explícita a los exhibidores locales a contratar las películas por lotes a través del denominado block-booking (cf. por ejemplo, Álvarez Monzoncillo y

5 Gideon Toury, «The Nature and Role of Norms in Literary Translation» Literature and Translation: New Perspectives in Literary Studies. Eds. James S. Holmes, José Lambert \& Raymond van den Broeck. (Leuven: Acco, 1978: 83-100). 
López Villanueva, 2006: 22 o Fernández-Santos, 2001) ${ }^{6}$, de tal modo que quien quiera obtener los derechos de un éxito de taquilla tendrá que comprar al mismo tiempo los de otras películas del mismo origen en las que quizá no esté tan interesado.

En la otra cara de la moneda, la de regulación de la traducción desde el país importador, son múltiples los ejemplos en los que distintos estudiosos presentan el carácter estratégico de los flujos de traducción, que distan mucho de ser casuales (cf. por ejemplo, Waisman 2005 sobre el cambio de autores importados tras la independencia argentina en 1816 o Antochi 2012 sobre censura y dirigismo cultural en el régimen comunista rumano durante gran parte de la segunda mitad del siglo xx) ${ }^{7}$.

Esta segunda faceta, la de selección importadora en función de los intereses culturales del receptor, es la que nos interesa en este estudio. Uno de los pilares de los estudios de traducción modernos radica en la preponderancia del polo de recepción a la hora de explicar tanto los criterios de selección de los textos que se traducen como el modo en que se realiza la traducción, esto es, el tipo de equivalencia que se escoge en cada caso. Si bien, como hemos señalado, se producen también situaciones en las que es el polo exportador el que hace uso de su hegemonía político económica para imponer aquello que se traduce, los estudios históricos en el seno de la disciplina parecen demostrar que es el polo de recepción el que toma casi siempre las decisiones finales al respecto, aunque como hemos visto no siempre sean decisiones

6 José María Álvarez Monzoncillo y Javier López Villanueva, La situación de la industria cinematográfica española: políticas públicas ante los mercados digitales (Documento de trabajo inédito 92/2006. Web. 10 de febrero de 2012). Elsa Fernández-Santos, «Las distribuidoras de cine admiten la venta de películas por lotes» El País, 9 de marzo de 2001. Web. 2 de febrero de 2012.

7 Sergio Waisman, Borges y la traducción. La irreverencia de la periferia / Borges and Translation. The Irreverence of the Periphery (Buenos Aires / Lewisburg: Adriana Hidalgo / Bucknell University Press, 2005).

Roxana-Mihaela Antochi, «Communist Ideology and Drama Translation in Romania». Aspects of Literary Translation. Building Linguistic and Cultural Bridge in Past and Present. Eds. Eva Membrives Parra; Miguel Ángel García Peinado y Albrecht Classen (Tübingen: Gunter Narr, 2012: 253-264). 
libres de presiones por parte del polo exportador cuando este se halla en posición de ejercer dicha influencia. En el caso de la literatura procedente de culturas no hegemónicas, como sucede con la costarricense, son los distintos polos de recepción los que actúan con autonomía casi absoluta tanto en la selección como en el modo de traducir ante la imposibilidad del polo emisor de condicionar ninguno de los dos. A ilustrar esos criterios y su carácter selectivo y distorsionante dedicaremos el resto de esta exposición a través de un análisis del modo en que se ha traducido la poesía costarricense a lo largo del siglo xx.

\section{La traducción de la poesía costarricense: criterios de selección y tipos de equivalencia}

Contrario a lo que suele pensarse, el género lírico en Costa Rica ha proliferado de manera constante, tanto en tendencias, temáticas y formas como en volumen, esto desde sus inicios a principios del siglo pasada. Valga decir que para finales de la década de 1990 se contaban en más de cuatrocientas las publicaciones de carácter lírico de origen costarricense, producidas por un conjunto de aproximadamente ciento cincuenta poetas y poetisas. Tal producción se ha dado de manera paralela y en continua interacción con las corrientes poético literarias que dieron forma a la poesía hispanoamericana actual.

Este último hecho, sin embargo, no impidió que en el país centroamericano se desarrollara una tradición lírica propia. En retrospectiva, dicho desarrollo se ve reflejado en la aparición de diversas tendencias, temas y formas poéticas distinguibles en la producción de distintas generaciones de poetas que surgieron a lo largo de los poco más de ciento diez años de evolución de la poesía costarricense. Así pues, se ha llegado a distinguir cinco generaciones en la 
poesía de Costa Rica, cada una de las cuales desarrolló características propias (vid. Monge, 1984, 1987, 1991, 1992, 1999 y 2005)

La primera de ellas, que surgiera junto con el siglo xx, mostraría claras filiaciones modernistas, con dejos del simbolismo y del esteticismo franceses, y un acentuado rechazo hacia el costumbrismo literario. Se gesta dicha generación entre 1900 y 1915, y su etapa de vigencia se extendería hasta 1930. A esta le seguiría una generación que florece durante las décadas de los años veinte y treinta: los posmodernistas, que, aunque de formación modernista, centraban su atención en el ámbito local, abandonando así las referencias a lo extranjero o universal. Dicha generación estará vigente entre 1925 y 1945 aproximadamente. La prevanguardia y sus tendencias experimentales hacen su entrada durante las últimas dos décadas de la primera mitad del siglo. Con dicha generación irrumpe en al ámbito costarricense la poesía contemporánea. A la prevanguardista le sigue, como sería de esperar, la generación vanguardista, con la cual se consolida el alejamiento de las formas «tradicionales» y la renovación del entorno poético costarricense. Esto último ocurría a partir de los años cuarenta. Finalmente, la segunda mitad del siglo atestiguó la aparición de la posvanguardia y de la poesía social en el país. Desde entonces y sin dejar de lado el tono social, la poesía costarricense vuelve sus ojos hacia el entorno globalizado en el que Costa Rica se inserta con cada vez más celeridad (vid. Monge, 1984, 1987, 1991, 1992, 1999, 2005; Drescher y Monge, 2012) .

El recuento anterior -demasiado breve y condensado- servirá como marco referencial a la hora de caracterizar no solo los criterios de

8 Carlos Francisco Monge, La imagen separada. Modelos ideológicos de la poesía (1950-1980) (San José: Ministerio de Cultura, Juventud y Deportes, 1984); «La escritura: pasión de la historia. La poesía contemporánea de Costa Rica» Revista Iberoamericana, LIII, 138-139 (1987): 303323; Códigos estéticos de la poesía de Costa Rica (1907-1967) (Tesis. Madrid: Universidad Complutense de Madrid, 1991); Antología crítica de la poesía de Costa Rica (San José: Editorial de la Universidad de Costa Rica, 1992); La rama de fresno: Ensayos sobre la literatura en Costa Rica (Heredia: EUNA, 1999); El vanguardismo literario en Costa Rica (Heredia: EUNA, 2005).

9 Carlos Francisco Monge y Victor Drescher, Contemporary Costa Rican Poetry. A Bilingual Anthology (Heredia: Escuela de Literatura y Ciencias del Lenguaje, 2012). 
selección y tipos de equivalencia relacionados a la traducción de poesía costarricense, sino también el carácter selectivo y distorsionante que tal actividad ha ejercido sobre su imagen en el ámbito internacional.

\section{Los polos, momentos, lenguas y medios de recepción}

¿Dónde, cuándo, en qué lenguas y en qué formas surgieron las traducciones de poesía costarricense que se produjeron durante el siglo pasado? Responder a tales preguntas es condición previa a la delimitación de los criterios que determinaron la selección de material original por traducir y la manera en que se realizaron aquellas traducciones.

Dicho esto, lo primero que cabe acotar son los contextos lingüísticos a los que llegaron las traducciones de poesía costarricense. El alemán, el inglés, el francés, el rumano y el sueco fueron las lenguas en que se llegó a leer la poesía costarricense, o más bien sus traducciones, durante el siglo pasado.

En cuanto a los espacios geopolíticos a los que arribó aquella poesía, hay que decir que la mayor cantidad de las traducciones bajo discusión se produjo en los Estados Unidos: catorce publicaciones fueron las que aparecieron en aquel país. Cuatro traducciones más se originaron en Francia. Inglaterra y Austria vieron la aparición de dos traducciones en cada caso. Canadá, Rumanía, Suecia y la misma Costa Rica fueron los espacios de producción de las restantes cuatro traducciones, una en cada país. Como ya será evidente, el número de traducciones mencionadas asciende a veintiséis. Tal número corresponde al $81,25 \%$ de lo que se había publicado hasta 2007. En cuanto a las traducciones que representan el restante $18,75 \%$, no ha sido posible tener acceso a ellas.

Todas aquellas traducciones se produjeron a partir de la segunda mitad del siglo pasado. Cinco de ellas surgieron durante las décadas de 1960 y 1970 en Estados Unidos y Rumanía; durante la década de los años ochenta se produjeron siete más en Canadá, Estados Unidos e Inglaterra; las últimas catorce se originaron durante los últimos diez años del siglo pasado e inicios del presente, en 
Austria, Estados Unidos, Francia y Suecia. Por otro lado, fueron dos las modalidades bajo las cuales se produjeron: un grupo, compuesto por siete volúmenes, estaba constituido por publicaciones de orden monográfico, constituidas por traducciones completas de determinadas obras o poemarios de origen costarricense. El segundo grupo, que suma diecinueve ejemplares, lo conformaban las traducciones de poemas individuales o pequeños conjuntos de poemas que se incluyeron en volúmenes de carácter antológico.

\section{La selección: lo que se ha traducido (y lo que no)}

A la diversidad de la oferta lírica costarricense naturalmente presente en el polo de partida -ya referida en páginas anteriores-, hay que contraponer lo limitado del panorama que se ofrecía en los polos de recepción por medio de la traducción.

Primero que todo cabe destacar el factor generacional o poético. Se ha dicho ya que son cinco las generaciones poéticas que configuran el universo histórico de la poesía costarricense, al menos hasta finales del siglo xx: modernista, posmodernista, prevanguardista, vanguardista y posvanguardista. No obstante, fue esta última generación la que recibió casi toda la atención en el ámbito (traductor) internacional. Las cifras al respecto así lo evidencian: más del $92 \%$ de lo que se tradujo se vinculaba a la tradición posvanguardista costarricense. El desbalance es mucho más notorio al revisar las cifras relativas al resto de tendencias: poco más del $30 \%$ tendía al vanguardismo, los vínculos con la prevanguardia y el posmodernismo se presentan solamente en poco más del $11 \%$ de lo que se tradujo, esto en cada caso, y un escaso $7 \%$ de lo traducido se relacionaba a la generación modernista de la poesía costarricense.

La situación en cuanto a los poetas y poetisas traducidos no hace sino ratificar el carácter parcializado de los criterios de selección, ya evidente en cuanto a las tendencias traducidas. Solo para comenzar, conviene mencionar que de ciento cincuenta y un poetas costarricenses investigados, solamente cincuenta y cuatro fueron 
traducidos. De tal cifra, cuarenta y dos contaban con un alto grado de visibilidad o reconocimiento como poetas dentro del entorno costarricense -otros siete con capital medio y cinco con capital bajo-, diecinueve fueron incluidos en más de tres de las veintiséis publicaciones mencionadas unos párrafos atrás, y cuarenta y uno (casi el $76 \%$ ) serían clasificados como poetas vanguardistas o posvanguardistas (dieciséis vanguardistas y veinticinco posvanguardistas). Cabe destacar que de tal selección se excluyó sobre todo a aquellos poetas con un nivel de reconocimiento medio o bajo -se tradujeron solamente doce de ochenta y seis poetas en tales condiciones- esto sin importar si se encontraban vinculados a las generaciones más traducidas, esto es, las de vanguardia y posvanguardia - mientras que de sesenta y cinco poetas con alto reconocimiento se tradujo, como ya se dijo, a cuarenta y dos-. Por supuesto que entre menor el reconocimiento y mayor la lejanía temporal y generacional, menores las posibilidades de cualquier poeta de llegar a ser traducido.

El panorama en términos temáticos resulta tan restringido y selectivo como los anteriores. Cerca de un $60 \%$ del material original escogido para ser traducido reflejaba tendencias temáticas de naturaleza feminista o femenina, en tanto que casi un $40 \%$ se asociaba a los temas de tipo social o sociopolítico. No sorprende entonces que gran cantidad de las traducciones estudiadas se encontraran en volúmenes dedicados a la literatura femenina centroamericana o latinoamericana traducida, ni tampoco que las figuras poéticas costarricenses más traducidas fuesen mujeres, gran parte de las cuales se afiliaban a las tendencias sociales y sociopolíticas de las generaciones de posvanguardia. A partir de este punto la presencia de otras temáticas es mucho más restringida: lo trascendentalista y lo humano o humanista están presentes en poco más del $19 \%$ en cada caso, y la temática de orden subjetivo se encuentra presente en solo el 11,50\% del material traducido. Un conjunto de ocho temas más se hace evidente en un $30 \%$ de los casos, a razón de 3,84 \% para cada tema particular. 
El mapa temático recién trazado implica que tópicos relacionados a la idealización del mundo, el cosmopolitismo, la búsqueda de la armonía, la contraposición urbanidad-ruralidad, la vuelta a lo primigenio y la palabra como forma de dar sentido al mundo, entre otros muy presentes sobre todo en las primeras generaciones poéticas costarricenses (vid. Monge, 1984, 1987, 1991, 1992, 1999 у 2005), no están representados en las traducciones de poesía costarricense producidas durante el siglo pasado. Aquellas traducciones, dicho sea de paso, se corresponden con las manifestaciones históricamente más contemporáneas, lingüísticamente más cotidianas e inusuales a la vez, y formalmente más libres de la lírica de Costa Rica. Son también aquellas que se alejan de patrones convencionales» de rima, verso y organización estrófica, así como del lenguaje de tipo elaborado y formal.

\section{La equivalencia: cómo se ha traducido}

Si como ya se dijo, la producción de las traducciones de poesía costarricense resulta ser una operación parcializada en cuanto a lo que se traduce, también lo es en cuanto a cómo se traduce el material original. Si bien es cierto las traducciones estudiadas parecen apegarse y buscar la reproducción de ciertos rasgos presentes en los originales, también resulta innegable que otros son anulados de manera sistemática.

Hay que iniciar aclarando que en general en las traducciones se percibe una tendencia dominante hacia el mimetismo, esto es, hacia la reproducción total de las características formales y de contenido de los textos originales. La mímesis, como estrategia traductora, dominó en más del $96 \%$ de los casos. No obstante, se observó cierta gradación en la aplicación de tal estrategia, sobre todo ante la presencia de rasgos formales «convencionales» en los poemas originales.

Así, tras analizar unos doscientos pares o binomios (poema original/traducción), se advierte que solamente en poco más del $19 \%$ de los casos la mímesis parece haber sido absoluta. En tales 
casos, los originales no presentaban rasgos «convencionales». Pero, por otro lado, la mímesis decae en el $69 \%$ de los casos en que los originales exhibían patrones fijos, ya fuesen de rima, versificación u organización estrófica. Esto significa que tales patrones fueron nulificados casi por completo durante el proceso de traducción. También menguó la práctica mimética en presencia de léxico formal o de sintaxis elaborada. Esto ocurrió en poco más del $19 \%$ de los casos, en los cuales, cabe aclarar, no se eliminó el rasgo por completo, sino que fue atenuado. Contrastan las cifras anteriores con las pocas instancias (el 7,68 \%) en que se presentaron diferencias significativas en cuanto al contenido.

La dinámica que los números suministrados reflejan de la operación traductora global es clara: los traductores se apegaron a los originales siempre y cuando estos no presentaran ni formas fijas de rima, versificación u organización estrófica, ni un lenguaje tendiente a lo formal o elaborado. Esto es tanto como decir que la traducción era respetuosa con la forma de representar el mundo del original costarricense siempre que dicho original se ajustase previamente a la imagen de la poesía -y de la poesía costarricense- que se buscaba difundir a través de la traducción.

Así las cosas, no resulta difícil empatar los criterios de selección -ya discutidos en la sección anterior-con las maneras de traducir recién bosquejadas: primero se selecciona la poesía más acorde con las necesidades del polo de recepción, que en este caso coincide con la menos convencional del polo de partida y, complementariamente, al traducir se nulifica precisamente cualquier traza de convencionalismos formales o lingüísticos presentes en los textos originales. El proceso de traducción, al igual que lo fuera con anterioridad el de selección, se transformó en un embudo por medio del cual se filtraron los rasgos poéticos más convencionales que escaparon a la primera purga. 


\section{La selectividad y la distorsión: la imagen proyectada}

Los procesos de selección y traducción anteriormente caracterizados y sus resultados configuraron una cierta imagen de la poesía costarricense en ámbitos internacionales determinados. Las formas libres, un lenguaje alejado de lo muy elaborado o formal, lo femenino, feminista, social y sociopolítico como temas centrales, y el posvanguardismo como marco poético principal son los rasgos que caracterizan tal imagen en los polos de recepción.

Si bien dicho perfil se corresponde en buena medida con parte de la tradición lírica costarricense, lo cierto es que excluye un gran segmento de la misma. A la vez termina por ratificar la ilusión de uniformidad que ya de por sí se ha cernido sobre una tradición poética que en la realidad se muestra heterogénea en sus formas, lenguajes, temáticas y tendencias poéticas. El resultado final es una imagen externa distorsionada y limitada, que para todo efecto no es ni equiparable ni conciliadora de la diversidad ni del desarrollo histórico real de la poesía costarricense.

Por otro lado, no está de más señalar que aquella misma configuración respondía también a las expectativas de los lectores meta, por un lado, en cuanto a lo que suponían era la poesía costarricense en términos temáticos -en tanto dependiente del contexto poético centroamericano y latinoamericano- y, por otra parte, en cuanto a lo que sabían era la poesía formalmente hablando dentro de sus propios entornos. La traducción se tornó en este caso en sinónimo de adecuación, al tiempo que es un mecanismo que acabó por ratificar las expectativas formales y de contenido de los lectores meta.

\section{Conclusiones}

En estas páginas hemos intentado mostrar un ejemplo real de cómo operan los mecanismos de desequilibrio traductor que investigadores y traductores deberían al menos replantearse. Una vez más los datos señalan al polo de recepción como el espacio dentro del 
cual se encontrarían habitualmente los mecanismos y actores encargados de los procesos de selección y producción relacionados a la traducción. Se encuentran tales actores en posición de dictaminar, a partir sus intereses, qué y cómo se traduce, al tiempo que construyen en algunos casos y ratifican en otros la imagen externa de aquello que es traducido y de sus productores originarios. La naturaleza neutral de la traducción, aquel mito del puente cultural pues, no es entonces menos ilusoria y fabricada que las imágenes sesgadas que puede llegar a producir. Así, en términos generales, la traducción resulta ser una actividad de tipo instrumental sin interés por sí misma para quienes hacen uso de ella, que se realiza de manera casi autónoma con respecto del polo de partida, pero con una alto grado de dependencia del polo de recepción, y en la cual el traductor suele ser un engranaje más de un mecanismo que otros ponen en marcha.

Para el traductor, ser consciente de la posibilidad de que su trabajo actúe como correa de transmisión de mecanismos de dominación o imágenes injustamente distorsionadas del otro puede constituir un toque de atención importante para actuar de modo que realmente supongan una compensación al injusto estado de las cosas. Ahora mismo, cientos si no miles de traductores actúan como voluntarios (cf. por ejemplo Granada Declaration, 2010; Simon, 2005; Baker, 2006; Calzada, 2007; etc. $)^{10}$ trabajando para muchas ONG en defensa de los derechos de los inmigrantes o en pos de traducciones socialmente relevantes de y a culturas minoritarias. Uno de los asuntos teóricos más candentes en los estudios de traducción es el de la ética del traductor y del intérprete, con un enfoque que trasciende ampliamente la cuestión de la fidelidad. En el campo de la interpretación

10 Varios autores, «Granada Declaration Traducción / Interpretación y Compromiso Social». Translation / Interpreting and Social Activism. Eds. Julie Boéri y Carol Maier (Granada: ECOS, 2010. Sin paginación. Web. 5 de febrero de 2013). Sherry Simon, ed., Traduction engagée / Translation and Social Activism. TTR 18, 2 (2005). Web. 5 de febrero de 2013. Mona Baker, «Translation and Activism: Emerging Patterns of Narrative Community» MR. The Massachusetts Review 47, 3 (2006): 462-484. María Calzada Pérez, «Translators and Translation Studies:

Scholars as Inoculators of Resistance» The Translator 13, 2 (2007): 243-269. 
social o comunitaria -también una novedad por sí mismo como objeto de estudio- se está debatiendo acaloradamente sobre la supuesta neutralidad de los intérpretes en situaciones de desequilibrio de poder manifiesto, como puede suceder con las entrevistas para solicitar asilo político, en consultas médicas o en los juicios - por no hablar de los interrogatorios tipo Guantánamo-. En el terreno de la traducción escrita, existen dos grandes temas de debate, el de la oposición al neocolonialismo (cf. Venuti, 1992, Cheung, 2007, Zauberga, 2000 et al. ${ }^{11}$ a través, entre otras medidas, de políticas de resistencia a la globalización entendida como homogeneización de sentido único, y, en segundo lugar, el debate que gira en torno a la tradicional invisibilidad del traductor (cf. Venuti, 1995) ${ }^{12}$, con la cuestión del dilema entre domesticación o exotización en primer plano.

11 Lawrence Venuti, ed., Rethinking Translation: Discourse, Subjectivity, Ideology (Londres: Routledge, 1992). Cheung, Martha P. Y., «On Thick Translation as a Mode of Cultural Representation». Across Boundaries: International Perspectives on Translation Studies. Eds. Dorothy Kenny y Kyongjoo Ryou (Newcastle: Cambridge Scholars Publishing, 2007: 22-37). Ieva Zauberga, «Rethinking Power Relations in Translation», Across Languages and Cultures I, 1 (2000): 49-56.

12 Lawrence Venuti, The Translator's Invisibility: a History of Translation (Londres: Routledge, 1995). 